\title{
Influence of Bin-width
}

\section{5\%-Bins}

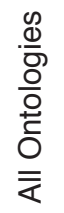

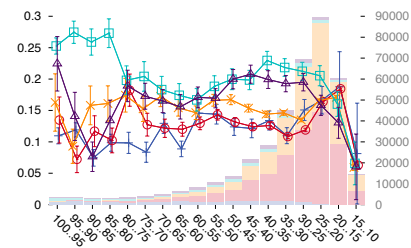

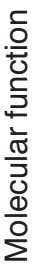

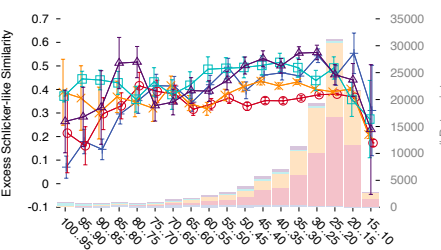

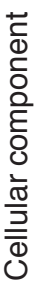

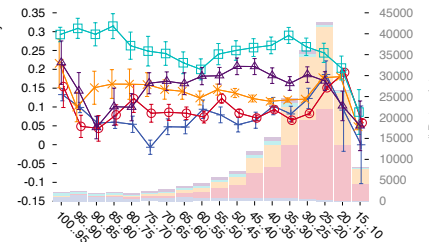

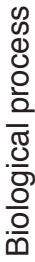

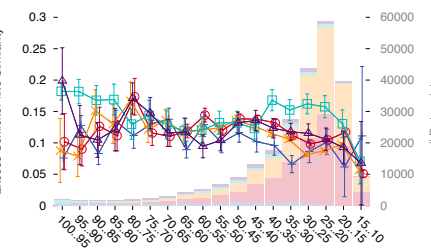

10\%-Bins
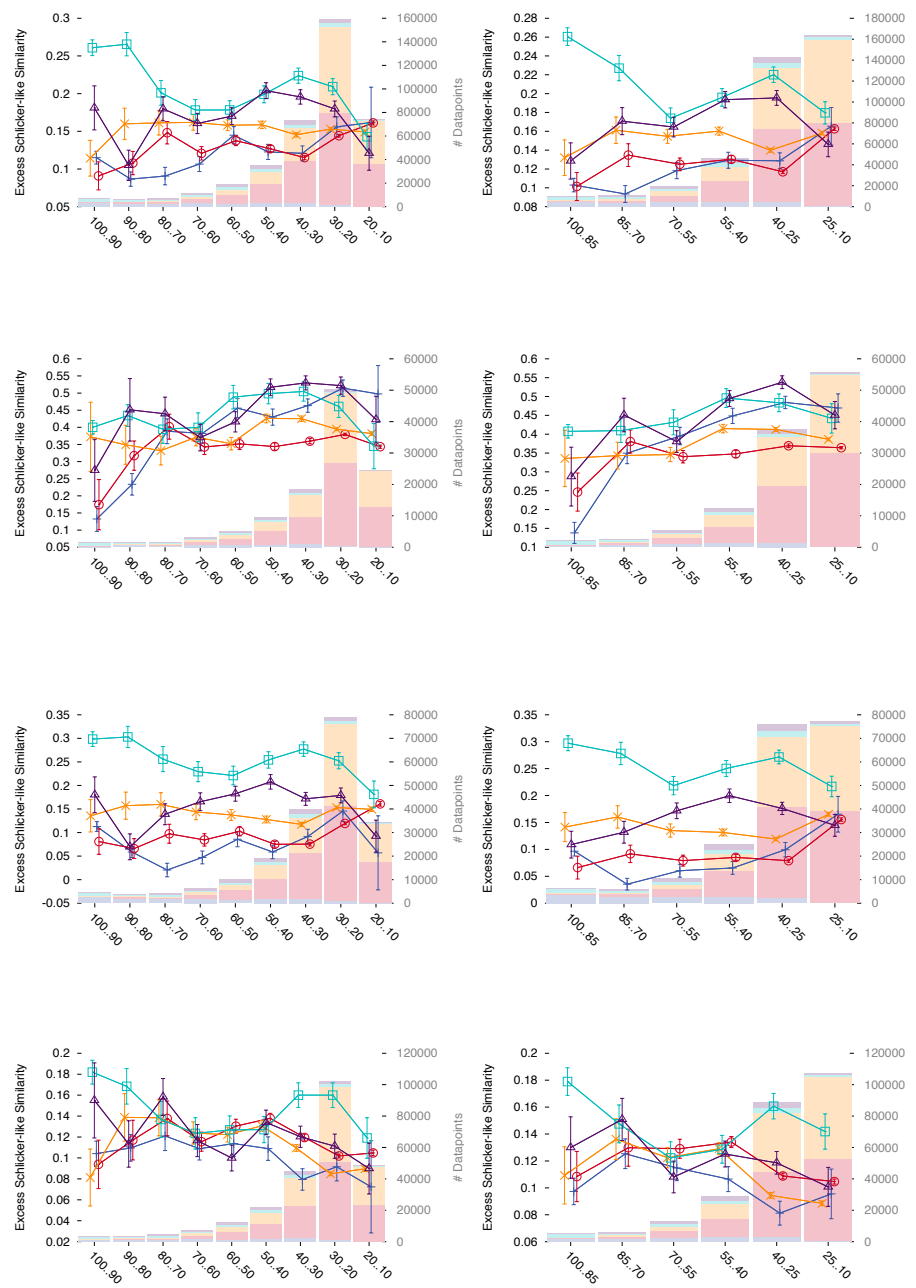

Percent Identity Within-spec. outparalogs + Between-spec. outparalogs $\forall$

$1: 1$ orthologs $\square$
Other orthologs $\triangle$
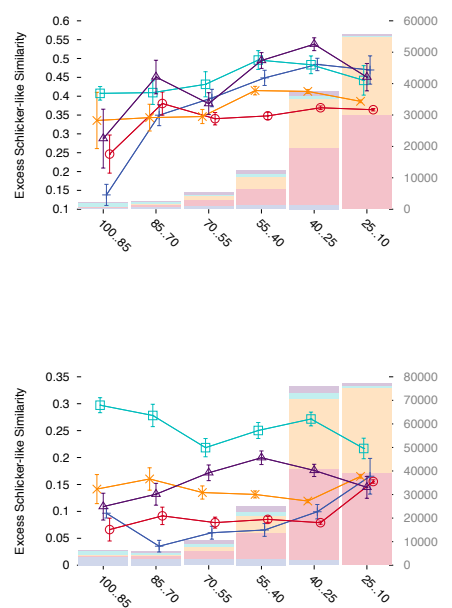

15\%-Bins
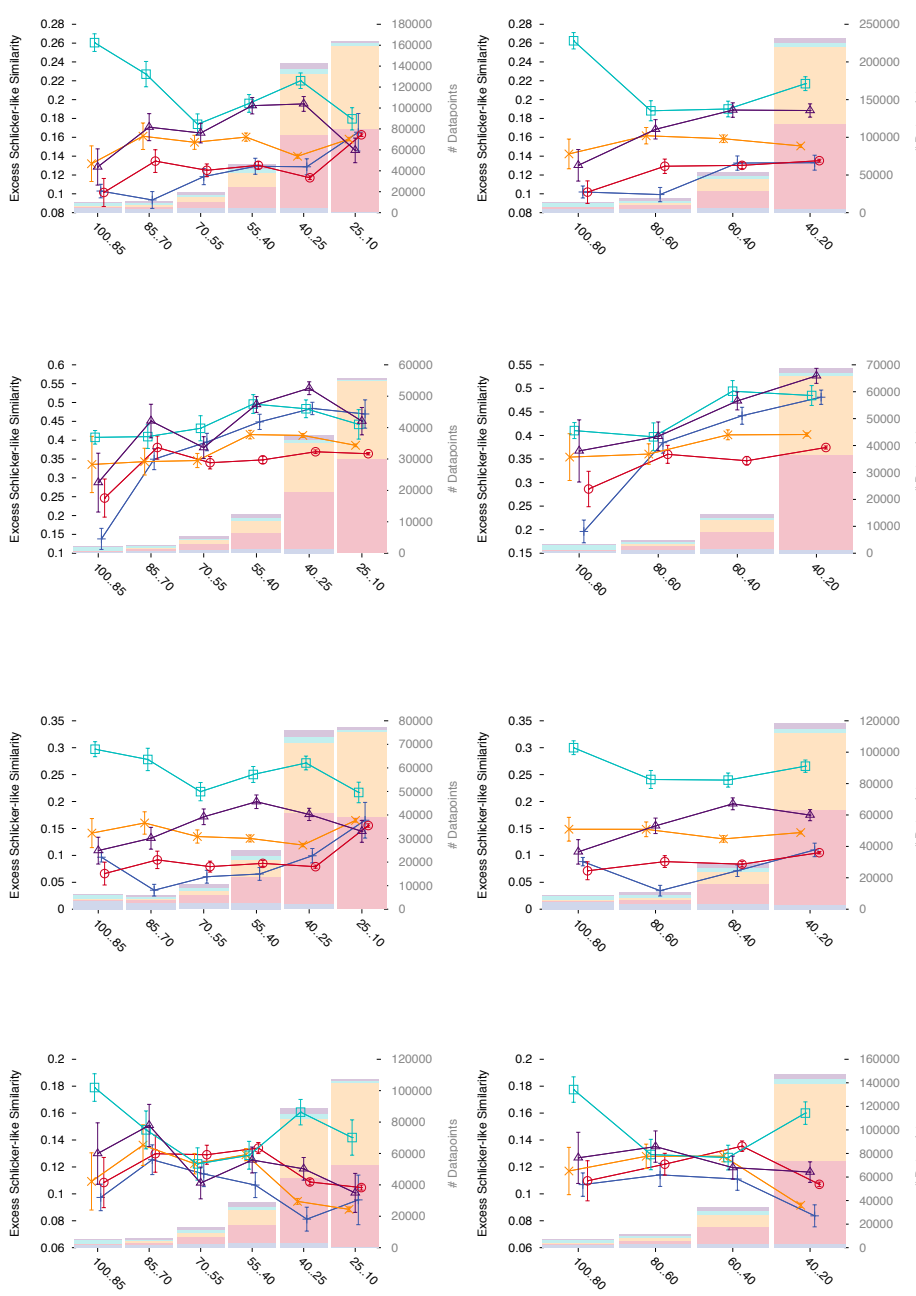